\title{
Temperature Effects on the Kinetics of Ferrocene and Cobaltocenium in Methyltriphenylphosphonium Bromide Based Deep Eutectic Solvents
}

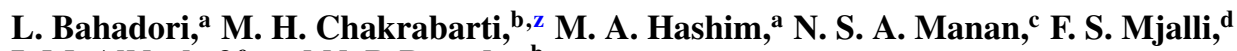 \\ I. M. AlNashef, ${ }^{\mathrm{e}}$ and N. P. Brandon ${ }^{\mathrm{b}}$ \\ ${ }^{a}$ Department of Chemical Engineering, Faculty of Engineering, University of Malaya, Kuala Lumpur 50603, Malaysia \\ ${ }^{b}$ Department of Earth Science and Engineering, Imperial College London, South Kensington, London SW7 2AZ, \\ United Kingdom \\ ${ }^{c}$ Department of Chemistry, Faculty of Science, University of Malaya, Kuala Lumpur 50603, Malaysia \\ ${ }^{d}$ Petroleum \& Chemical Engineering Department, Sultan Qaboos University, Muscat 123, Oman \\ ${ }^{e}$ Department of Chemical and Environmental Engineering, Masdar Institute of Science and Technology, Abu Dhabi, \\ United Arab Emirates
}

\begin{abstract}
The oxidation of ferrocene $\left(\mathrm{Fc} / \mathrm{Fc}^{+}\right)$and reduction of cobaltocenium $\left(\mathrm{Cc}^{+} / \mathrm{Cc}\right)$ under different temperatures has been studied by cyclic voltammetry and double potential step chronoamperometry in deep eutectic solvents (DESs) consisting of methyltriphenylphosphonium bromide salt with tri-ethylene glycol, glycerol or ethylene glycol as hydrogen bond donors. The temperature dependence of the measured physical properties of DESs (such as viscosity and conductivity) is discussed in detail. The kinetics of the redox couples are studied using cyclic voltammetry, and the standard heterogeneous electron transfer rate constant, $k^{0}$ is found to be of the order of $10^{-5}$ to $10^{-4} \mathrm{cms}^{-1}$ at different temperatures. The diffusion coefficient, $D$, of $\mathrm{Fc}$ and $\mathrm{Cc}^{+}$is determined to lie between 8.28 $\times 10^{-10}$ to $6.65 \times 10^{-9} \mathrm{~cm}^{2} \mathrm{~s}^{-1}$. These results show that both $k^{0}$ and $D$ increase with temperature in the studied DESs. In addition, better kinetic parameters for the DES with ethylene glycol as hydrogen bond donor means that this could be evaluated favorably as both solvents and electrolytes for redox flow cells.

(C) The Author(s) 2015. Published by ECS. This is an open access article distributed under the terms of the Creative Commons Attribution 4.0 License (CC BY, http://creativecommons.org/licenses/by/4.0/), which permits unrestricted reuse of the work in any medium, provided the original work is properly cited. [DOI: 10.1149/2.0381509jes] All rights reserved.
\end{abstract}

Manuscript submitted April 30, 2015; revised manuscript received June 9, 2015. Published June 18, 2015.

In recent years, to overcome the toxicity and high price of ionic liquids (ILs), deep eutectic solvents (DESs) have been investigated as potential alternatives. ${ }^{1-3}$ DESs share many characteristics of conventional ILs (e.g., they have intrinsic ionic conductivity, low-volatility, biodegradability, high thermal and chemical stability, good electrochemical stability as well as non-flammability). In addition, they are simple to synthesize on a large scale. ${ }^{4-6}$ These properties have been explored for applications such as solvents for electrodeposition and electropolishing, ${ }^{7-9}$ electrochemistry, ${ }^{10}$ separation processes,${ }^{11}$ chemical and enzymatic reactions, ${ }^{12}$ biochemistry ${ }^{13}$ as well as organic and inorganic syntheses. ${ }^{14,15}$ In its most common form, a DES is a eutectic mixture of an organic salt (ammonium or phosphonium) and a hydrogen bond donor (HBD), that is made up of different components such as amides, metal salts, alcohols, carboxylic acids and amines that may be used as complexing agents (typically an H-bond donor). ${ }^{16,17}$ A DES has a melting point that is far below that of its individual constituents. This is because the complexing agent interacts with the anion and increases its effective size. This, in turn, decreases the anionic interaction with the cation thereby reducing the melting point of the mixture. ${ }^{18}$

Organometallic redox couples such as ferrocene/ferrocenium $\left(\mathrm{Fc} / \mathrm{Fc}^{+}\right)$or cobaltocenium/cobaltocene $\left(\mathrm{Cc}^{+} / \mathrm{Cc}\right)$ are frequently used as a standard reference for non-aqueous solvents in conjunction with a quasi-reference electrode (QRE) to control and evaluate electrode potentials. ${ }^{19-22} \mathrm{Fc}$ is often used as an ideal internal reference system for comparison of redox processes in different ILs, although Torriero et al. ${ }^{23}$ indicate that the standard redox potential of $\mathrm{Fc}$ is dependent on the solvation effects of the solvent and supporting electrolyte used. $\mathrm{Fc}$ is often poorly soluble in some ILs, mostly in those with high viscosity. In contrast, $\mathrm{Cc}$ is generally soluble in ILs, where the reduction of the $\mathrm{Cc}^{+} / \mathrm{Cc}$ appears to be an ideal reversible process. ${ }^{21,22}$ There are some unexpected complexities in the literature as to the behavior of $\mathrm{Fc} / \mathrm{Fc}^{+}$in a range of commonly-used ILs. For example, the diffusion coefficient of $\mathrm{Fc}$ is a function of concentration, nonlinear peak current versus $\mathrm{Fc}$ concentration relationships ${ }^{24}$ as well as nonlinear correlations between the enthalpy of vaporization and molar surface energy

${ }^{\mathrm{z} E-m a i l: ~ m o h a m m e d h a r u n 77 @ y a h o o . c o m ~}$ of the $\left[\mathrm{C}_{n} \mathrm{C}_{1} \mathrm{Im}\right]\left[\mathrm{BF}_{4}\right]$ ILs. ${ }^{25,26}$ With the exception of some electrochemical studies in organic solvents at different temperatures, ${ }^{27-29}$ the investigation has been performed at room temperature. In the case of ILs, the voltammetry of both $\mathrm{Fc}$ and $\mathrm{Cc}$ was evaluated over a range of temperatures $^{21}$ and the kinetics of the $\mathrm{Fc} / \mathrm{Fc}^{+}$electrochemical system was investigated in the temperature range of 298-373 K. ${ }^{30}$

Despite such progress, no fundamental study on the effect of temperature on $\mathrm{Fc} / \mathrm{Fc}^{+}$oxidation and $\mathrm{Cc}^{+} / \mathrm{Cc}$ reduction processes in DESs is available. DESs, just as ILs, perform the dual function of electrolyte and solvent and hence represent a different kind of medium for electrochemical applications. In the present work the electrochemical data and kinetics of the $\mathrm{Fc} / \mathrm{Fc}^{+}$and $\mathrm{Cc}^{+} / \mathrm{Cc}$ redox couples obtained with cyclic voltammetry and chronoamperometry in Type III DESs (there are four different types of DESs as described in the literature $)^{1,31}$ based on a quaternary phosphonium salt and three different alcohol-based hydrogen bond donors are reported over a range of temperatures. In addition, the effect of temperature on the physicochemical properties of the studied DESs is investigated.

\section{Experimental}

Materials. - In this work methyltriphenylphosphonium bromide $\left(\mathrm{C}_{19} \mathrm{H}_{18} \mathrm{PBr}\right)$ was used as a quaternary phosphonium salt while triethylene glycol $\left(\mathrm{C}_{6} \mathrm{H}_{14} \mathrm{O}_{4}\right)$, glycerol $\left(\mathrm{C}_{3} \mathrm{H}_{8} \mathrm{O}_{3}\right)$ or ethylene glycol $\left(\mathrm{C}_{2} \mathrm{H}_{6} \mathrm{O}_{2}\right)$ were employed as hydrogen bond donors. All chemicals were supplied by Merck (Germany) with high purity ( $\geq 98 \%$ ). These chemicals were stored in an inert glove box (Innovative Technology, Pure Lab ${ }^{\mathrm{HE}}$, USA) purged with argon (oxygen-free) with no additional purification being required. The water mass fraction of the chemicals (as per the manufacturer's guide) was $<10^{-3}$.

Preparation of DESs. - The eutectic mixtures were prepared by following the method prescribed earlier in several publications. ${ }^{3,8,32}$ Briefly, each DES solution was prepared by stirring the quaternary phosphonium salt and HBD mixture vigorously with a magnetic stirrer, in the stated proportions (Table I), at $373 \mathrm{~K}$ and atmospheric pressure, while observing the formation of a homogeneous colorless liquid. The synthesized DESs were stored in the argon-filled glove box with a moisture content of less than $1 \mathrm{ppm}$ during the entire study. 
Table I. Physicochemical properties of phosphonium-based DESs.

\begin{tabular}{|c|c|c|c|c|c|c|c|c|c|}
\hline \multirow[b]{2}{*}{ DESs } & \multicolumn{2}{|l|}{ Formulae } & \multirow{2}{*}{$\begin{array}{l}\text { Molar } \\
\text { ratio }\end{array}$} & \multirow{2}{*}{$\begin{array}{c}M_{w} \\
\left(\mathrm{~g} \mathrm{~mol}^{-1}\right)\end{array}$} & \multirow{2}{*}{$\begin{array}{c}\text { Melting } \\
\text { Point (K) }\end{array}$} & \multirow[b]{2}{*}{$\rho\left(\mathrm{g} \mathrm{cm}^{-3}\right)$} & \multirow[b]{2}{*}{$\eta(\mathrm{mPa} s)$} & \multirow[b]{2}{*}{$\sigma\left(\mathrm{mS} \mathrm{cm}^{-1}\right)$} & \multirow[b]{2}{*}{$\mathrm{pH}$} \\
\hline & Salt & $\mathrm{HBD}^{\mathrm{a}}$ & & & & & & & \\
\hline $\mathrm{C}_{19} \mathrm{H}_{18} \mathrm{BrP} / \mathrm{TEG}$ & $\begin{array}{c}\mathrm{C}_{19} \mathrm{H}_{18} \mathrm{BrP} \\
\text { Methyltriphenylphosphonium } \\
\text { bromide }\end{array}$ & $\begin{array}{c}\mathrm{C}_{6} \mathrm{H}_{14} \mathrm{O}_{4} \\
\text { Triethylene } \\
\text { glycol }\end{array}$ & $1: 4$ & 191.58 & 254 & 1.20 & 270 & 0.62 & 5.53 \\
\hline $\mathrm{C}_{19} \mathrm{H}_{18} \mathrm{BrP} /$ Glycerol & $\begin{array}{c}\mathrm{C}_{19} \mathrm{H}_{18} \mathrm{BrP} \\
\text { Methyltriphenylphosphonium } \\
\text { bromide }\end{array}$ & $\begin{array}{l}\mathrm{C}_{3} \mathrm{H}_{8} \mathrm{O}_{3} \\
\text { Glycerol }\end{array}$ & $1: 3$ & 158.38 & $267^{\mathrm{b}}$ & 1.29 & $3040^{\mathrm{b}}$ & $0.08^{b}$ & 5.60 \\
\hline $\mathrm{C}_{19} \mathrm{H}_{18} \mathrm{BrP} / \mathrm{EG}$ & $\begin{array}{c}\mathrm{C}_{19} \mathrm{H}_{18} \mathrm{BrP} \\
\text { Methyltriphenylphosphonium } \\
\text { bromide }\end{array}$ & $\begin{array}{c}\mathrm{C}_{2} \mathrm{H}_{6} \mathrm{O}_{2} \\
\text { Ethylene } \\
\text { glycol }\end{array}$ & $1: 2$ & 160.46 & $230^{\mathrm{b}}$ & 1.25 & $213^{\mathrm{b}}$ & $1.43^{\mathrm{b}}$ & 6.12 \\
\hline
\end{tabular}

${ }^{\mathrm{a}} \mathrm{HBD}=$ Hydrogen Bond Donor

${ }^{\mathrm{b}}$ Data from Ref. 30

The preparation process was complete within 3-5 h. Table I shows the DESs studied in the present work.

Physicochemical properties test.- Conductivity measurement of synthesized DESs was carried out with DZS-708 Multi-parameter analyzer, which was calibrated using a $0.001 \mathrm{M}$ standard solution of $\mathrm{KCl}$ (Merck) at different temperatures. The viscosities of the DESs were obtained by averaging each measurement at least three to five times, using a Brookfield DV-II + Pro EXTRA instrument. The standard uncertainty in viscosity measurements did not exceed $\pm 1 \%$ in this study. The densities were measured at various temperatures using a DMA 4100 Density Meter (Anton Paar, Austria) with three replicates for each reading with an uncertainty of $\pm 0.00008 \mathrm{~g} \cdot \mathrm{cm}^{-3}$. The adjustment of the density meter was checked using water (degassed and distilled) at $298 \mathrm{~K}$ and compared with the corresponding value in density tables. The results exhibited a difference of $\pm 0.00005 \mathrm{~g} \mathrm{~cm}^{-3}$ which showed good accuracy. The $\mathrm{pH}$ was determined by means of a Metrohm $\mathrm{pH}$ meter, which was calibrated using a standard $\mathrm{pH}$ buffer solution. The temperature control of DESs during the measurement of all properties, from 298 to $368 \mathrm{~K}$, was ensured by means of a Wisecircu thermostatic water bath.

Electrochemical measurements.- All electrochemical experiments were performed with a computer-controlled $i$-Autolab potentiostat (Metrohm PGSTAT302N) using a typical three-electrode cell that was assembled within a Faraday cage inside the dry argon-filled glove box to minimize electrochemical noise. A platinum microelectrode (20 $\mu \mathrm{m}$ diameter) and a Glassy Carbon macro-electrode (GC, $3 \mathrm{~mm}$ diameter) were used as working electrodes. Silver wire (immersed in $65 \% \mathrm{HNO}_{3}$ prior to experiments, then rinsed thoroughly with water and ethanol) was used as the quasi-reference electrode (AgQRE) while Pt. wire was employed as the counter electrode. The working electrodes were polished prior to each experiment with $0.25 \mu \mathrm{m}$ alumina slurry (Wirth Buehler) and ultrasonically rinsed in acetone. The limiting potentials for the electrochemical window of each DES were arbitrarily determined as the potential corresponding to the current density beyond $0.2 \mathrm{~mA} \mathrm{~cm}^{-2}$, which was selected as the cutoff current density for comparison purposes.

\section{Results and Discussion}

Preparation and characterization of DESs. - The structures of DESs from the association between the phosphonium salt and three alcohol-based HBDs are summarized in Table I. The same is applicable for the fundamental physicochemical properties of conductivity, viscosity, density, melting point and $\mathrm{pH}$ of all synthesized DESs (for a better understanding of the interactions in these compounds). All of these alcohol-based DESs in the present study are liquid at room temperature.

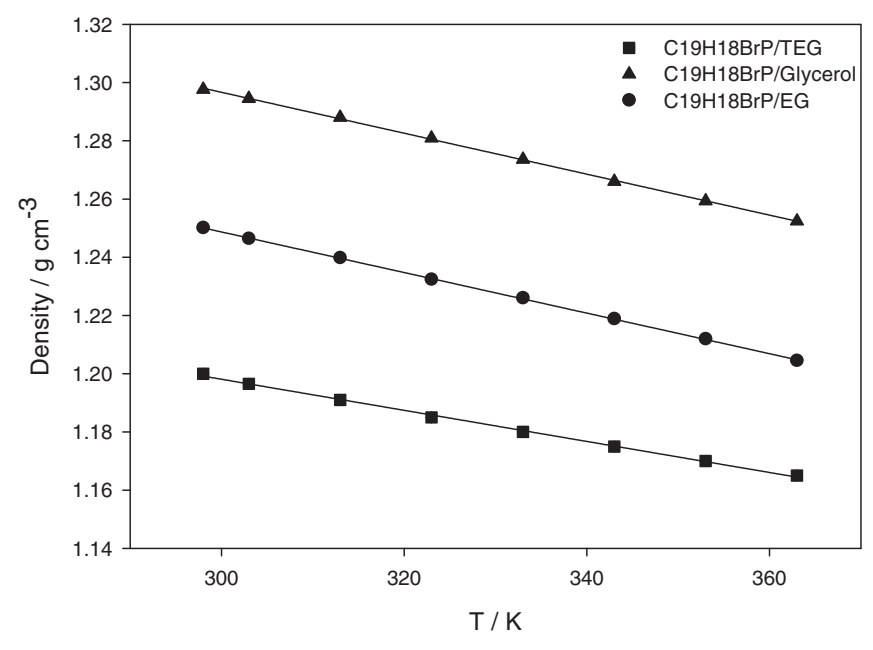

Figure 1. Dependence of densities ( $\rho$ ) on temperature for the DESs employed in this investigation.

The densities of the DESs were determined in the temperature range of 298-363 $\mathrm{K}$ at atmospheric pressure. As expected, it was observed (Figure 1) that the densities of the DESs decreased linearly with increasing temperature because of thermal expansion. The difference in the values of density for the studied DESs could be ascribed to a different molecular association or packing of the DES and the difference in the density of the HBDs. In general, there was good agreement between the values obtained in this work and those reported in the literature. ${ }^{33}$ The following equation fitted the experimental data for the densities $(\rho)$ of the DESs well over the entire temperature range:

$$
\rho=A T+B
$$

Where $T$ is the absolute temperature (K) while $A$ and $B$ are empirical constants that depend on the type of DES. The adjustable parameters of Equation 1 for the density of the phosphonium based DESs are displayed in Table II. As shown in Table I, $\mathrm{C}_{19} \mathrm{H}_{18} \mathrm{BrP} /$ Glycerol has a higher density due to a higher intermolecular packing.

Table II. The adjustable parameters for density and $\mathrm{pH}$ of phosphonium-based DESs.

A

\begin{tabular}{cccccr} 
& \multicolumn{2}{c}{$\mathrm{A}$} & & \multicolumn{2}{c}{$\mathrm{B}$} \\
\cline { 2 - 3 } DESs & Density & $\mathrm{pH}$ & & Density & $\mathrm{pH}$ \\
\hline $\mathrm{C}_{19} \mathrm{H}_{18} \mathrm{BrP} / \mathrm{TEG}$ & -0.0005 & 0.0231 & & 1.3582 & -1.3567 \\
$\mathrm{C}_{19} \mathrm{H}_{18} \mathrm{BrP} / \mathrm{Glycerol}$ & -0.0007 & -0.0075 & & 1.5077 & 7.8614 \\
$\mathrm{C}_{19} \mathrm{H}_{18} \mathrm{BrP} / \mathrm{EG}$ & -0.0007 & -0.0055 & & 1.4578 & 7.7286
\end{tabular}




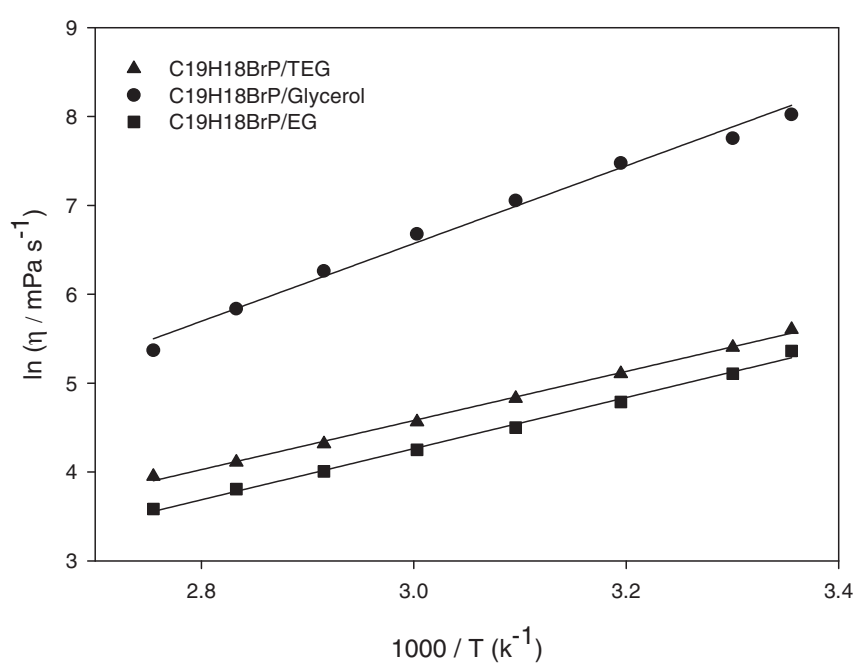

Figure 2. Arrhenius plot of viscosity $(\eta)$ for the DESs used.

It is important to establish a reliable viscosity database for electrochemical studies, due to its strong effect on the rate of mass transport within the solution that significantly affects diffusion of species in media such as ionic liquids. ${ }^{34}$ The viscosity is usually influenced by the interaction of the salt to HBD and their ability to coordinate. The relative capacity to form hydrogen bonds, anionic species, size, higher alkalinity, van der Waals forces and the size of the cation can affect the viscosity values. Figure 2 indicates that with an increase in temperature from 298 to $363 \mathrm{~K}$, the viscosity of the DESs decreased due to the higher mobility of ions. DESs with the glycerol HBD exhibit higher viscosities than other alcohol based DESs, which may be ascribed to the presence of a comprehensive hydrogen bond network between each component because of the presence of three hydroxyl groups in each molecule of glycerol; this results in a lower mobility of free species within the DES. As shown in Figure 2, the temperature dependence of the viscosity values is fitted using the Arrhenius equation, which describes the temperature dependence for non-associating electrolytes. ${ }^{35}$

$$
\ln \eta=\ln \eta_{0}+\frac{E_{\eta}}{R T}
$$

Where $T$ is the temperature, $E_{\eta}$ is the activation energy, $\eta$ is the viscosity, $\eta_{o}$ is a constant and $R$ is the gas constant. The regression correlation coefficients are of values higher than 0.97 showing a reasonably good fit. The $E_{\eta}, \eta_{o}$ and sums of square errors in measurements are depicted in Table III.

Ionic conductivity is a function of both the mobility and number of carrier ions. Conductivity evolution can be attributed to various factors, such as the geometrical and electronic structure of the salts and hydrogen bond donors, the diffusion coefficient of protons and hydrogen-bond interactions. It needs to be noted that the conductivity of $\mathrm{C}_{19} \mathrm{H}_{18} \mathrm{BrP} / \mathrm{EG}$ is much higher than that for $\mathrm{C}_{19} \mathrm{H}_{18} \mathrm{BrP} / \mathrm{TEG}$ and $\mathrm{C}_{19} \mathrm{H}_{18} \mathrm{BrP} /$ Glycerol. This may be attributed to the high viscosity of glycerol. As the temperature rises, conductivity of DESs generally increases significantly as a consequence of faster movement of ions at higher temperatures as well as lower viscosity of the neat DES. The

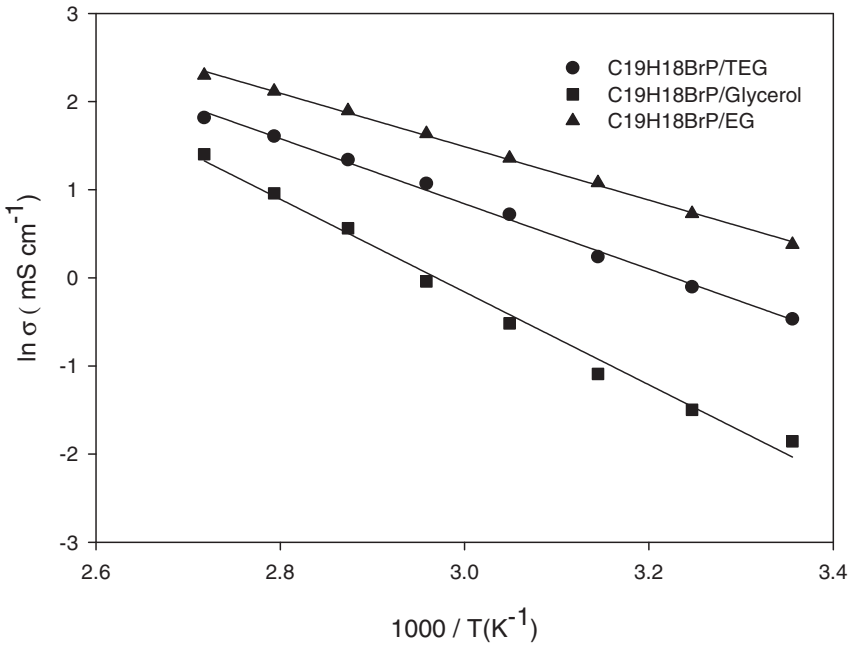

Figure 3. Arrhenius plot of specific conductivity $(\sigma)$ for the DESs used.

temperature dependence of conductivity for the DESs is depicted in Figure 3 . The conductivity of DESs $(\sigma)$ varies over the entire temperature range according to Equation $3: 36$

$$
\ln \sigma=\ln \sigma_{\mathrm{o}}+\frac{\mathrm{E}_{\sigma}}{\mathrm{RT}}
$$

Where $T$ is the temperature, $\sigma_{o}$ is a constant and $E_{\sigma}$ is the activation energy for conduction. Consequently, from Equation $3^{36} E_{\sigma}, \sigma_{o}$ and sums of square errors are shown in Table IV. The regression correlation coefficients are of values higher than 0.96 . Molar conductivity $\Lambda\left(\mathrm{m}^{2} \mathrm{~S}\right.$ $\mathrm{mol}^{-1}$ ) of the DESs as electrolytes was calculated using the expression $\Lambda=V_{e} \sigma$. The equivalent weight $\left(V_{e}\right)$ of the DESs is measured from the experimental density using the equation $V_{e}=M / \rho$, where $\rho$ is the density and $M$ is the molar mass. ${ }^{34}$

In order to discuss the ionic behavior, the plot of the equivalent conductivity against the inverse of viscosity (Walden plot) for the phosphonium based DESs over a temperature range of $298-363 \mathrm{~K}$ is shown in Figure 4 . When the conductivity is strongly correlated with the viscosity, the Walden rule can be written as follows:

$$
\Lambda \eta^{\alpha}=C
$$

Where $\alpha$ is the slope of the line in the Walden plot, which reflects the decoupling of the ions and $C$ (Walden product) is a temperaturedependent constant. This scheme provides a useful basis for classifying and arranging the ILs $\mathrm{s}^{34,37}$ due to the practical measure for examining the ion pairing problem in electrolytes. It also helps in understanding the relationship between conductivity and low vapor pressure that is, otherwise, not so apparent. The dotted ideal line in Figure 4 represents the data for aqueous $\mathrm{KCl}$ solutions at high dilution, which corresponds to a system composed of equally mobile and fully dissociated ions. ${ }^{38}$ The curve for $\mathrm{C}_{19} \mathrm{H}_{18} \mathrm{BrP} / \mathrm{TEG}$ and $\mathrm{C}_{19} \mathrm{H}_{18} \mathrm{BrP} / \mathrm{EG}$ lie below the deal Walden line. $\mathrm{C}_{19} \mathrm{H}_{18} \mathrm{BrP} /$ Glycerol examined from Walden plots lie on the ideal line which indicates that it is good a IL. ${ }^{39}$ The deviations of the Walden plot of these DESs from the ideal line show an increased electrostatic interaction between the phosphonium salts and the hydrogen bond donors. In this study, we also

Table III. Regression parameters for viscosity and conductivity of phosphonium-based DESs.

\begin{tabular}{ccccrr} 
DESs & $\eta_{0} / \mathrm{mPa} \mathrm{s}$ & $E_{\eta} / \mathrm{kJ} \mathrm{mol}^{-1}$ & $\mathrm{SS} E_{\eta}$ & $\sigma_{o} / \mathrm{mS} \mathrm{cm}^{-1}$ & $E_{\sigma} / \mathrm{kJ} \mathrm{mol}^{-1}$ \\
\hline $\mathrm{C}_{19} \mathrm{H}_{18} \mathrm{BrP} / \mathrm{TEG}$ & 3.70 & 22.97 & 0.031 & 12.30 & 25.32 \\
$\mathrm{C}_{19} \mathrm{H}_{18} \mathrm{BrP} /$ Glycerol & 6.55 & 36.36 & 0.089 & 14.30 & 0.032 \\
$\mathrm{C}_{19} \mathrm{H}_{18} \mathrm{BrP} / \mathrm{EG}$ & 4.37 & 23.93 & 0.042 & 11.93 & 39.85 \\
\hline
\end{tabular}

$\mathrm{SS}=$ Sum of Square 
Table IV. The experimental voltammetric data for $\mathrm{Fc} / \mathrm{Fc}^{+}$and $\mathrm{Cc}^{+} / \mathrm{Cc}$ in DESs with different operating temperatures.

\begin{tabular}{|c|c|c|c|c|c|c|c|c|c|c|c|c|c|}
\hline \multirow[b]{2}{*}{ DESs } & \multirow[b]{2}{*}{$T / \mathrm{K}$} & \multicolumn{6}{|c|}{$\mathrm{Fc} / \mathrm{Fc}^{+}$} & \multicolumn{6}{|c|}{$\mathrm{Cc}^{+} / \mathrm{Cc}$} \\
\hline & & $j_{p a} / \mathrm{mA} \mathrm{cm}^{-2}$ & $j_{p c} / \mathrm{mA} \mathrm{cm}^{-2}$ & $E_{p a} / \mathrm{V}$ & $E_{p c} / \mathrm{V}$ & $\Delta E_{p} / \mathrm{V}$ & $E_{1 / 2} / \mathrm{V}$ & $j_{p a} / \mathrm{mA} \mathrm{cm}^{-2}$ & $j_{p c} / \mathrm{mA} \mathrm{cm}^{-2}$ & $E_{p a} / \mathrm{V}$ & $E_{p c} / \mathrm{V}$ & $\Delta E_{p} / \mathrm{V}$ & $E_{1 / 2} / \mathrm{V}$ \\
\hline \multirow[t]{5}{*}{$\mathrm{C}_{19} \mathrm{H}_{18} \mathrm{BrP} / \mathrm{TEG}$} & 298 & 0.016 & -0.011 & 0.435 & 0.336 & 0.099 & 0.385 & 0.096 & -0.165 & -0.661 & -0.731 & 0.070 & -0.696 \\
\hline & 308 & 0.021 & -0.013 & 0.421 & 0.325 & 0.096 & 0.373 & 0.146 & -0.203 & -0.655 & -0.724 & 0.069 & -0.689 \\
\hline & 318 & 0.027 & -0.017 & 0.411 & 0.319 & 0.092 & 0.365 & 0.192 & -0.247 & -0.648 & -0.715 & 0.067 & -0.681 \\
\hline & 328 & 0.030 & -0.020 & 0.401 & 0.312 & 0.089 & 0.356 & 0.223 & -0.291 & -0.641 & -0.706 & 0.065 & -0.673 \\
\hline & 338 & 0.035 & -0.024 & 0.392 & 0.306 & 0.086 & 0.349 & 0.258 & -0.342 & -0.637 & -0.700 & 0.063 & -0.668 \\
\hline \multirow{5}{*}{$\begin{array}{c}\mathrm{C}_{19} \mathrm{H}_{18} \mathrm{BrP} / \\
\text { Glycerol }\end{array}$} & 298 & 0.019 & -0.022 & 0.417 & 0.340 & 0.073 & 0.380 & 0.186 & -0.218 & -0.645 & -0.741 & 0.096 & -0.693 \\
\hline & 308 & 0.028 & -0.023 & 0.409 & 0.338 & 0.071 & 0.373 & 0.203 & -0.246 & -0.641 & -0.736 & 0.095 & -0.688 \\
\hline & 318 & 0.035 & -0.025 & 0.398 & 0.330 & 0.068 & 0.364 & 0.235 & -0.302 & -0.635 & -0.727 & 0.092 & -0.681 \\
\hline & 328 & 0.046 & -0.028 & 0.389 & 0.323 & 0.066 & 0.356 & 0.258 & -0.333 & -0.629 & -0.718 & 0.089 & -0.673 \\
\hline & 338 & 0.052 & -0.031 & 0.381 & 0.319 & 0.062 & 0.350 & 0.297 & -0.389 & -0.621 & -0.709 & 0.088 & -0.665 \\
\hline \multirow[t]{5}{*}{$\mathrm{C}_{19} \mathrm{H}_{18} \mathrm{BrP} / \mathrm{EG}$} & 298 & 0.098 & -0.089 & 0.433 & 0.342 & 0.091 & 0.387 & 0.297 & -0.325 & -0.658 & -0.752 & 0.094 & -0.705 \\
\hline & 308 & 0.110 & -0.092 & 0.425 & 0.334 & 0.091 & 0.379 & 0.339 & -0.362 & -0.652 & -0.744 & 0.092 & -0.698 \\
\hline & 318 & 0.131 & -0.125 & 0.419 & 0.331 & 0.088 & 0.375 & 0.351 & -0.403 & -0.649 & -0.738 & 0.089 & -0.693 \\
\hline & 328 & 0.159 & -0.142 & 0.411 & 0.325 & 0.086 & 0.368 & 0.379 & -0.456 & -0.638 & -0.725 & 0.087 & -0.681 \\
\hline & 338 & 0.171 & -0.161 & 0.405 & 0.320 & 0.085 & 0.362 & 0.402 & -0.509 & -0.634 & -0.717 & 0.083 & -0.675 \\
\hline
\end{tabular}

measured the $\mathrm{pH}$ of the synthesized DESs as a function of temperature as indicated in Figure 5. The temperature dependence of $\mathrm{pH}$ was fitted linearly and the parameters for fitting are depicted in Table II. These results indicate that the $\mathrm{pH}$ increases with rising temperature for $\mathrm{C}_{19} \mathrm{H}_{18} \mathrm{BrP} / \mathrm{TEG}$. On the other hand, the $\mathrm{pH}$ of $\mathrm{C}_{19} \mathrm{H}_{18} \mathrm{BrP} /$ Glycerol and $\mathrm{C}_{19} \mathrm{H}_{18} \mathrm{BrP} / \mathrm{EG}$ tends to decrease with temperature.

Electrochemical stability. - The electrochemical stability of the electrolyte is an important design criterion for proper reactor operation. Electrochemical stability depends on the type of electrodes, the measurement conditions, the references employed, and the arbitrary current cutoff used to define the onset of redox processes (typically between 0.1 and $\left.1.0 \mathrm{~mA} \mathrm{~cm}^{-2}\right){ }^{40}$ The cathodic stability potential of DESs is mainly ascribed to the reduction of the cation (salt), while the anodic stability of DESs is affected by the oxidation potential of the anionic (HBDs) part. However, Figure 6 indicated that the cathodic limiting potentials do vary even when the salt present is common. The variation of these potentials infers that the interaction between the salt and HBDs plays a significant role in the electrochemical stability.

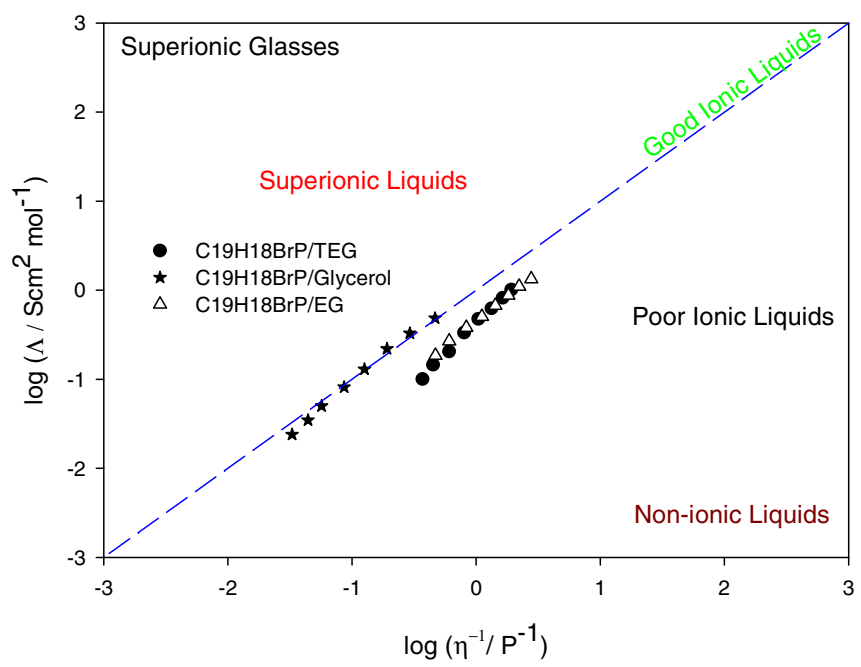

Figure 4. Walden plots for the phosphonium based DESs, where $\Lambda$ is the molar conductivity and $\eta^{-1}$ is the fluidity. The dotted line indicates the data for a dilute aqueous $\mathrm{KCl}$ solution to fix the position of the ideal Walden line (for good ILs).
For particular applications (e.g., supercapacitors), it is the overall potential window that matters, while in other applications, the actual anodic and cathodic limits with respect to an arbitrary reference electrode (normal hydrogen or saturated calomel electrodes are typical examples) or the standard potential of a reversible redox couple in the solvent of interest (e.g., ferrocene) is the limiting factor. Typical cyclic voltammograms (at room temperature and a scan rate of $100 \mathrm{mV} \mathrm{s}^{-1}$ ) recorded at $\mathrm{GC}$ and $\mathrm{Pt}$ microelectrodes to determine the limiting reduction and oxidation potentials of the neat DESs are given in Figures 6a and $6 \mathrm{~b}$ (where the current cutoff value was $0.2 \mathrm{~mA} \mathrm{~cm}{ }^{-2}$ ). It is very clear from Figure 6 that the type of HBD plays a significant role in determining the electrochemical window of the DES. As expected, the electrochemical window of TEG $>$ Glycerol $>$ EG. The reduction hump at around $0.5 \mathrm{~V}$ for EG DES could be due to capacitance current or perhaps due to an irreversible process of adsorbed species.

The voltammetric parameter for $\mathrm{FC}_{\mathrm{C}} \mathrm{Fc}^{+}$and $\mathrm{Cc}^{+} / \mathrm{Cc}$ in DESs as function of temperature.- The quantitative relationship (determined from voltammetric data) of two IUPAC recommended standard potential references in different phosphonium-based DESs is evaluated here as a function of temperature. The $\mathrm{Fc} / \mathrm{Fc}^{+}$couple is commonly used to provide a reference potential scale in voltammetric studies. In addition, Bond and co-workers have also presented the $\mathrm{Cc}^{+} / \mathrm{Cc}$ redox couple as a functional reference scale in organic solvents as well

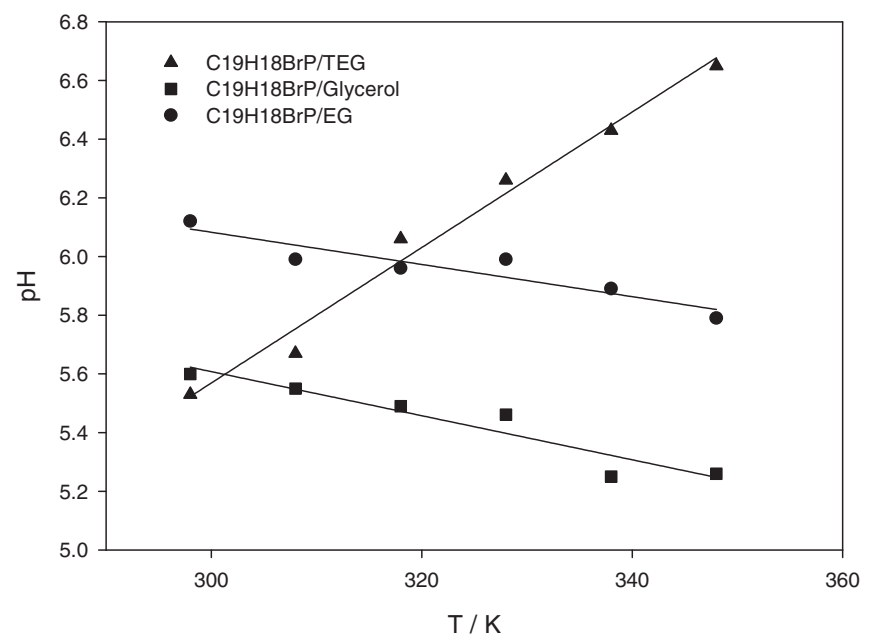

Figure 5. Temperature-dependency of $\mathrm{pH}$ of selected DESs. 

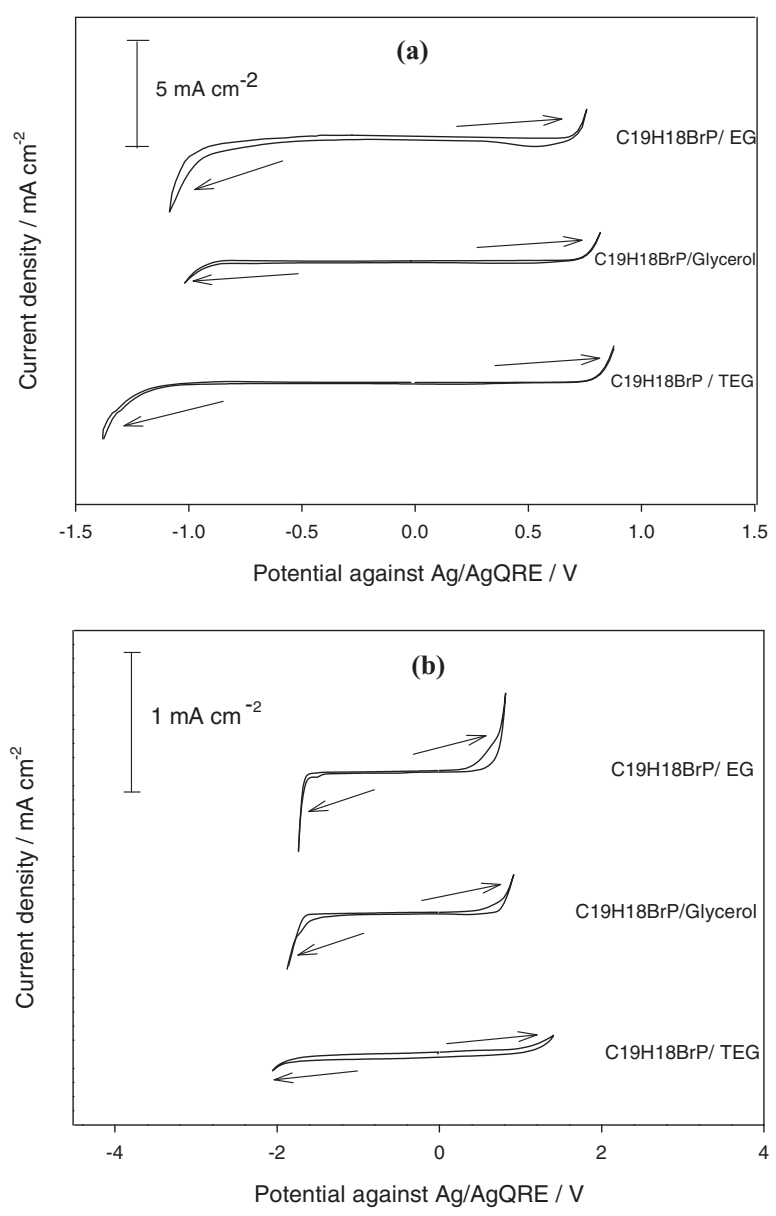

Figure 6. (a) Electrochemical stability obtained using Pt. Microelectrode; (b) Electrochemical stability of phosphonium based DESs using GC working electrode.

as in ILs. ${ }^{20,22,41}$ In the investigated DESs, $\mathrm{Fc}$ and $\mathrm{Cc}^{+}$demonstrate reversible one-electron redox processes that can be described by the following reactions:

$$
\begin{aligned}
& {\left[\mathrm{Fc}\left(\mathrm{C}_{5} \mathrm{H}_{5}\right)_{2}\right] \rightleftarrows\left[\mathrm{Fc}\left(\mathrm{C}_{5} \mathrm{H}_{5}\right)_{2}\right]^{+}+\mathrm{e}^{-}} \\
& {\left[\mathrm{Co}\left(\mathrm{C}_{5} \mathrm{H}_{5}\right)_{2}\right]^{+}+\mathrm{e}^{-} \rightleftarrows\left[\mathrm{Co}\left(\mathrm{C}_{5} \mathrm{H}_{5}\right)_{2}\right]}
\end{aligned}
$$

The temperature dependence of representative cyclic voltammograms of $\mathrm{Fc}$ and $\mathrm{Cc}^{+}$in $\mathrm{C}_{19} \mathrm{H}_{18} \mathrm{BrP} / \mathrm{EG}$ are shown in Figures 7 and 8, respectively. Voltammetric data obtained from individually prepared $10 \mathrm{mM}$ solutions of $\mathrm{Fc}$ and $\mathrm{Cc}^{+}$by using a $\mathrm{GC}$ working electrode at different scan rates over a temperature range of 298-348 K are summarized in Table IV. The difference between the corresponding anodic and cathodic peaks $\left(\Delta E_{p}\right)$ observed in Table IV varies between 62-99 $\mathrm{mV}$ for $\mathrm{Fc} / \mathrm{Fc}^{+}$and $63-96 \mathrm{mV}$ for $\mathrm{Cc}^{+} / \mathrm{Cc}$. As expected, $\Delta E_{p}$ decreases with the increase in temperature due to faster heterogeneous electron transfer kinetics. The differences between the experimental and theoretical values, $0.059 \mathrm{~V}$, of $\Delta E_{p}$ for a reversible process are attributed to uncompensated solution resistance $\left(R_{u}\right){ }^{42,43}$ The half wave potential $\left(E_{1 / 2}\right)$ of the redox couples mentioned above against the $\mathrm{Ag}$ wire quasi reference electrode is calculated from the difference in the anodic peaks $\left(E_{\mathrm{pa}}\right)$ and $\Delta E_{p}$.

$$
E_{1 / 2}=E_{p a}-\frac{\Delta E_{p}}{2}
$$

Considerable drifts in potential were discerned for the Ag wire QRE dipped directly in DESs including electroactive compounds. However, segregating the Ag wire immersed in DESs from the bulk solution through a glass frit eliminated this drift in potential. The
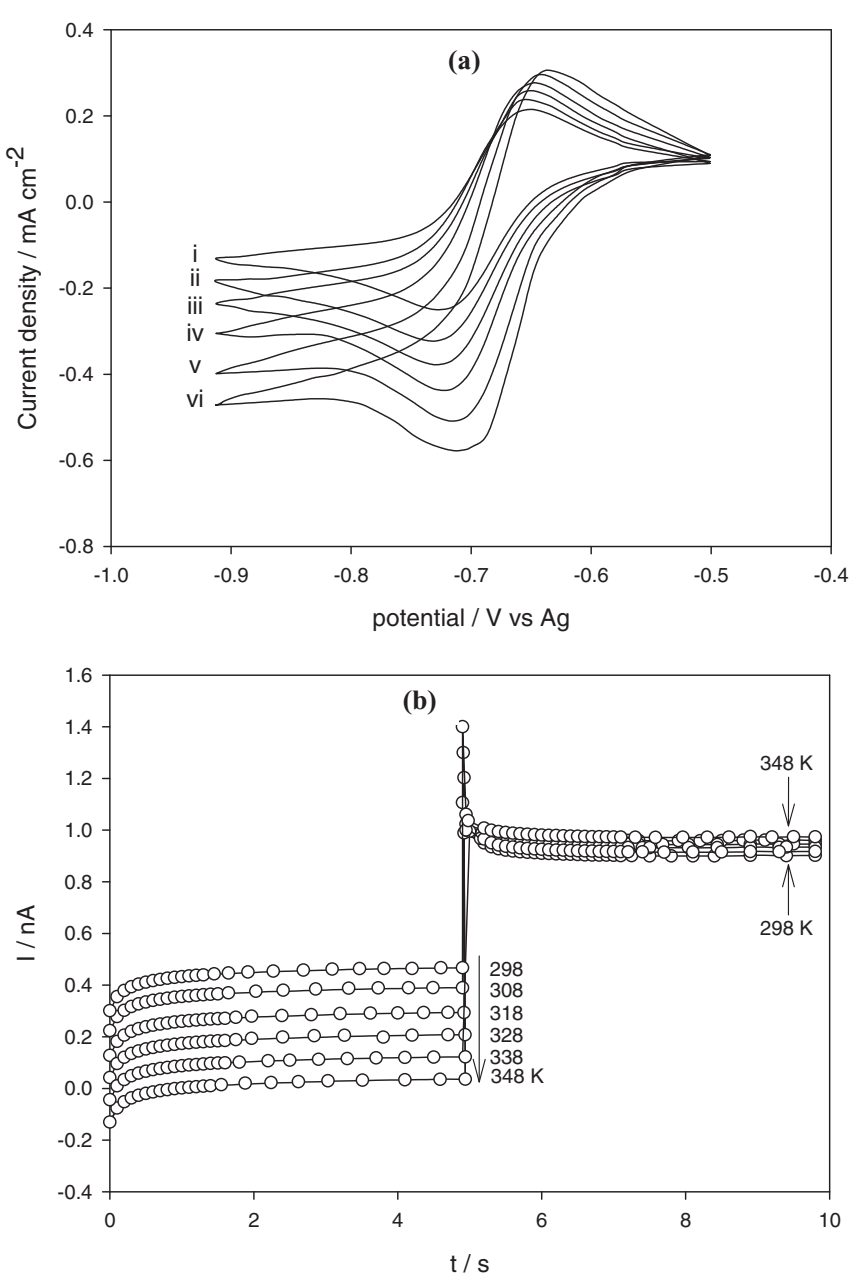

Figure 7. (a) Cyclic voltammetry for the reduction of $\mathrm{Cc}^{+}$in the used DESs at varying temperatures of (i) $298 \mathrm{~K}$, (ii) $308 \mathrm{~K}$, (iii) $318 \mathrm{~K}$, (iv) $328 \mathrm{~K}$, (v) $338 \mathrm{~K}$ and (vi) $348 \mathrm{~K}$, at $100 \mathrm{mV} \mathrm{s}^{-1}$; (b) Double potential step chronoamperometry measured on the same system across the $\mathrm{Cc}^{+} / \mathrm{Cc}$ at temperatures of 298,308 , 318,338 and $348 \mathrm{~K}$.

$E_{1 / 2}$ was demonstrated to be inversely proportional to temperature. Table IV indicated that $E_{1 / 2}$ shifted to more negative potentials for the oxidation of $\mathrm{Fc}$ and more positive potentials for the reduction of $\mathrm{Cc}^{+}$, which could be attributed to donor-acceptor Lewis-type interactions. ${ }^{44}$ Additionally, the peak current ratio of the reverse and the forward scans $\left(i_{\mathrm{pa}} / i_{\mathrm{pc}}\right)$ was greater than unity and was dependent on the temperature in all the studied DESs over the entire scan range (as well as for all scan rates studied). Figures $7 \mathrm{a}$ and $8 \mathrm{~b}$ showed that the peak currents increased with rising temperature for the cathodic side in case of $\mathrm{Cc}^{+}$ and the anodic side in case of Fc.

Determination of diffusion coefficient activation energy for $\mathrm{Fc}_{\mathrm{C}} \mathrm{Fc}^{+}$ and $C c^{+} / C c$. - Double potential step chronoamperometry at a Pt. microelectrode was carried out to evaluate the diffusion coefficients, $D$, of both $\mathrm{Fc}$ and $\mathrm{Cc}^{+}$in DESs at various temperatures. The technique was performed using a sample time of $0.01 \mathrm{~s}$. The pre-treatment step comprised holding the potential at a point corresponding to the passage of zero faradaic current (with $20 \mathrm{~s}$ pre equilibration time), after which the potential was stepped from +0.10 to $+0.60 \mathrm{~V}$ (oxidation of $\mathrm{Fc}$ to $\mathrm{Fc}^{+}$with respect to the AgQRE) and -0.50 to $-0.90 \mathrm{~V}$ (reduction of $\mathrm{Cc}^{+}$to $\mathrm{Cc}$ ), and the current was measured for $5 \mathrm{~s}$. The potential was then stepped back to $+0.10 \mathrm{~V}$ (reduction of $\mathrm{Fc}^{+}$to $\mathrm{Fc}$ ) and $-0.50 \mathrm{~V}$ (oxidation of $\mathrm{Cc}$ to $\mathrm{Cc}^{+}$), and the current response was measured for a further $5 \mathrm{~s}$. The software package Origin 7.0 (Microcal Software Inc.) was used to fit the first potential step experimental data. The 

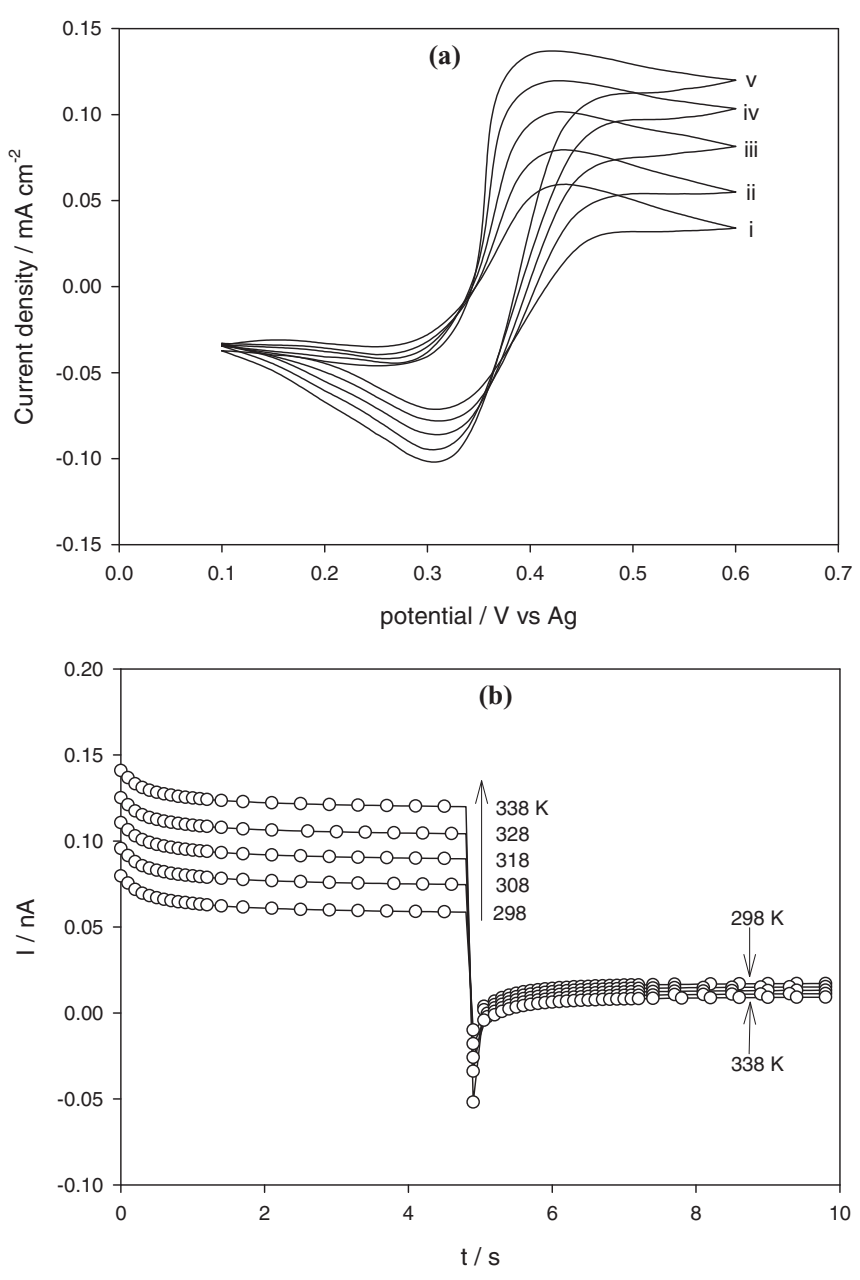

Figure 8. Cyclic voltammetry for the oxidation of $\mathrm{Fc}$ in the DESs at varying temperatures of (i) $298 \mathrm{~K}$, (ii) $308 \mathrm{~K}$, (iii) $318 \mathrm{~K}$, (iv) $328 \mathrm{~K}$ and (v) $338 \mathrm{~K}$, at $100 \mathrm{mV} \mathrm{s}^{-1}$; (b) Double potential step chronoamperometry measured on the same system across the $\mathrm{Fc} / \mathrm{Fc}^{+}$at temperatures of $298,308,318$ and $338 \mathrm{~K}$.

equations empirically derived by Shoup and Szabo ${ }^{45}$ were regressed to the potential-current data using a least squares minimization algorithm. The correlation below (shown in Equations 8-10) describes the
Table VI. Activation energies of the diffusion coefficients and rate constants for $\mathrm{Fc} / \mathrm{Fc}^{+}$and $\mathrm{Cc}^{+} / \mathrm{Cc}$ in studied DESs.

\begin{tabular}{ccccc} 
DESs & $\begin{array}{c}E_{D}(\mathrm{Fc}) / \\
\mathrm{kJ} \mathrm{mol}^{-1}\end{array}$ & $\begin{array}{c}E_{D}\left(\mathrm{Cc}^{+}\right) / \\
\mathrm{kJ} \mathrm{mol}^{-1}\end{array}$ & $\begin{array}{c}E_{k}{ }^{0}(\mathrm{Fc}) / \\
\mathrm{kJ} \mathrm{mol}^{-1}\end{array}$ & $\begin{array}{c}E_{k}{ }^{0}\left(\mathrm{Cc}^{+}\right) / \\
\mathrm{kJ} \mathrm{mol}^{-1}\end{array}$ \\
\hline $\mathrm{C}_{19} \mathrm{H}_{18} \mathrm{BrP} / \mathrm{TEG}$ & 28.36 & 29.45 & 26.30 & 31.48 \\
$\mathrm{C}_{19} \mathrm{H}_{18} \mathrm{BrP} /$ Glycerol & 49.35 & 52.32 & 38.23 & 58.41 \\
$\mathrm{C}_{19} \mathrm{H}_{18} \mathrm{BrP} / \mathrm{EG}$ & 24.05 & 22.93 & 22.07 & 27.63
\end{tabular}

current response to within an accuracy of $0.6 \%$

$$
\begin{gathered}
I=-4 n F D c r_{d} f(\tau) \\
f(\tau)=0.7854+0.8863 \tau^{-1 / 2}+0.2146 \exp \left(-0.7823 \tau^{-1 / 2}\right) \\
\tau=\frac{4 D t}{r_{d}^{2}}
\end{gathered}
$$

Here, $r_{\mathrm{d}}$ represents the radius of the microdisk electrode, $D$ is the diffusion coefficient, $F$ is Faraday's constant, $c$ is the bulk concentration of the electro-active species, $t$ is the time, and $n$ is the number of electrons transferred. An example of an experimental and best-fit theoretical chronoamperometric transients for the $\mathrm{Fc} / \mathrm{Fc}^{+}$and $\mathrm{Cc}^{+} / \mathrm{Cc}$ redox couples in $\mathrm{C}_{19} \mathrm{H}_{18} \mathrm{BrP} / \mathrm{EG}$ are shown in Figures $7 \mathrm{~b}$ and $8 \mathrm{~b}$. As the temperature increases the limiting currents of the first step decrease systematically and the trend of the second step becomes less steep for both $\mathrm{Fc}$ and $\mathrm{Cc}^{+}$.

As expected, the diffusion coefficient of the electroactive species increased systematically with temperature (Table V). To calculate the activation energy for diffusion, $E_{D}$, the $D_{F c}$ and $D_{C c+}$ were analyzed in terms of the Arrhenius equation:

$$
D=D_{0} \exp \left(\frac{-E_{D}}{R T}\right)
$$

Where $D_{0}$ is a constant corresponding to the hypothetical diffusion coefficient at infinite temperature, and $D$ is the diffusion coefficient of the electroactive species.

Figures $9 \mathrm{a}$ and $9 \mathrm{~b}$ show plots of $\ln D$ vs. $T^{-1}$ for the oxidized and reduced forms of $\mathrm{Fc}$ and $\mathrm{Cc}^{+}$, which display good linearity over the range of temperatures studied. Table VI shows $E_{D}$, which was calculated from the gradient of the best-fit line $\left(\mathrm{R}^{2}>0.97\right.$ for $\mathrm{Fc}$ and $\mathrm{R}^{2}>0.98$ for $\left.\mathrm{Cc}^{+}\right)$. These values are similar with $E_{\eta}$ for DESs, which was estimated from viscosity dependence temperature measurements and summarized in Table III. It is also observed that the less viscous DESs have correspondingly smaller activation energies.

Table V. Kinetic parameters and diffusion coefficients for $\mathrm{Fc} / \mathrm{Fc}^{+}$and $\mathrm{Cc}^{+} / \mathrm{Cc}$ in DESs at various temperatures.

\begin{tabular}{cccccc} 
DESs & $T / \mathrm{K}$ & $D_{F c} / \mathrm{cm}^{2} \mathrm{~s}^{-1}$ & $D_{C c+} / \mathrm{cm}^{2} \mathrm{~s}^{-1}$ & $k^{\circ}{ } / \mathrm{cm} \mathrm{s}^{-1}$ \\
\hline $\mathrm{C}_{19} \mathrm{H}_{18} \mathrm{BrP} / \mathrm{TEG}$ & 298 & $3.76 \times 10^{-9}( \pm 0.07)$ & $2.85 \times 10^{-9}( \pm 0.05)$ & $1.38 \times 10^{-4}( \pm 0.08)$ & $1.14 \times 10^{-4}( \pm 0.05)$ \\
& 308 & $4.23 \times 10^{-9}( \pm 0.04)$ & $3.69 \times 10^{-9}( \pm 0.08)$ & $2.58 \times 10^{-4}( \pm 0.06)$ & $3.21 \times 10^{-4}( \pm 0.08)$ \\
& 318 & $4.54 \times 10^{-9}( \pm 0.08)$ & $4.21 \times 10^{-9}( \pm 0.07)$ & $3.14 \times 10^{-4}( \pm 0.05)$ & $3.96 \times 10^{-4}( \pm 0.07)$ \\
& 328 & $5.20 \times 10^{-9}( \pm 0.06)$ & $4.76 \times 10^{-9}( \pm 0.05)$ & $5.27 \times 10^{-4}( \pm 0.08)$ & $4.08 \times 10^{-4}( \pm 0.09)$ \\
& 338 & $5.63 \times 10^{-9}( \pm 0.09)$ & $5.24 \times 10^{-9}( \pm 0.04)$ & $6.56 \times 10^{-4}( \pm 0.09)$ & $4.97 \times 10^{-4}( \pm 0.06)$ \\
$\mathrm{C}_{19} \mathrm{H}_{18} \mathrm{BrP} /$ Glycerol & 298 & $9.08 \times 10^{-10}( \pm 0.05)$ & $8.28 \times 10^{-10}( \pm 0.09)$ & $2.11 \times 10^{-5}( \pm 0.09)$ & $1.91 \times 10^{-5}( \pm 0.06)$ \\
& 308 & $9.92 \times 10^{-10}( \pm 0.06)$ & $9.22 \times 10^{-10}( \pm 0.08)$ & $4.38 \times 10^{-5}( \pm 0.05)$ & $2.42 \times 10^{-5}( \pm 0.08)$ \\
& 318 & $1.38 \times 10^{-9}( \pm 0.09)$ & $1.98 \times 10^{-9}( \pm 0.05)$ & $5.16 \times 10^{-5}( \pm 0.04)$ & $4.53 \times 10^{-5}( \pm 0.05)$ \\
& 328 & $2.12 \times 10^{-9}( \pm 0.07)$ & $2.12 \times 10^{-9}( \pm 0.06)$ & $5.56 \times 10^{-5}( \pm 0.09)$ & $5.32 \times 10^{-5}( \pm 0.08)$ \\
& 338 & $2.86 \times 10^{-9}( \pm 0.05)$ & $2.66 \times 10^{-9}( \pm 0.05)$ & $5.96 \times 10^{-5}( \pm 0.07)$ & $6.12 \times 10^{-5}( \pm 0.09)$ \\
$\mathrm{C}_{19} \mathrm{H}_{18} \mathrm{BrP} / \mathrm{EG}$ & 298 & $4.23 \times 10^{-9}( \pm 0.08)$ & $3.74 \times 10^{-9}( \pm 0.05)$ & $1.71 \times 10^{-4}( \pm 0.07)$ & $1.02 \times 10^{-4}( \pm 0.06)$ \\
& 308 & $4.92 \times 10^{-9}( \pm 0.07)$ & $4.56 \times 10^{-9}( \pm 0.06)$ & $3.88 \times 10^{-4}( \pm 0.06)$ & $2.56 \times 10^{-4}( \pm 0.06)$ \\
& 318 & $5.53 \times 10^{-9}( \pm 0.05)$ & $5.02 \times 10^{-9}( \pm 0.09)$ & $5.68 \times 10^{-4}( \pm 0.08)$ & $4.56 \times 10^{-4}( \pm 0.08)$ \\
& 328 & $6.12 \times 10^{-9}( \pm 0.04)$ & $5.51 \times 10^{-9}( \pm 0.06)$ & $7.43 \times 10^{-4}( \pm 0.05)$ & $6.31 \times 10^{-4}( \pm 0.05)$ \\
& 338 & $6.65 \times 10^{-9}( \pm 0.08)$ & $6.28 \times 10^{-9}( \pm 0.07)$ & $8.96 \times 10^{-4}( \pm 0.05)$ & $7.84 \times 10^{-4}( \pm 0.05)$
\end{tabular}

Error bars calculated from the standard deviation from four experimental repetitions. 

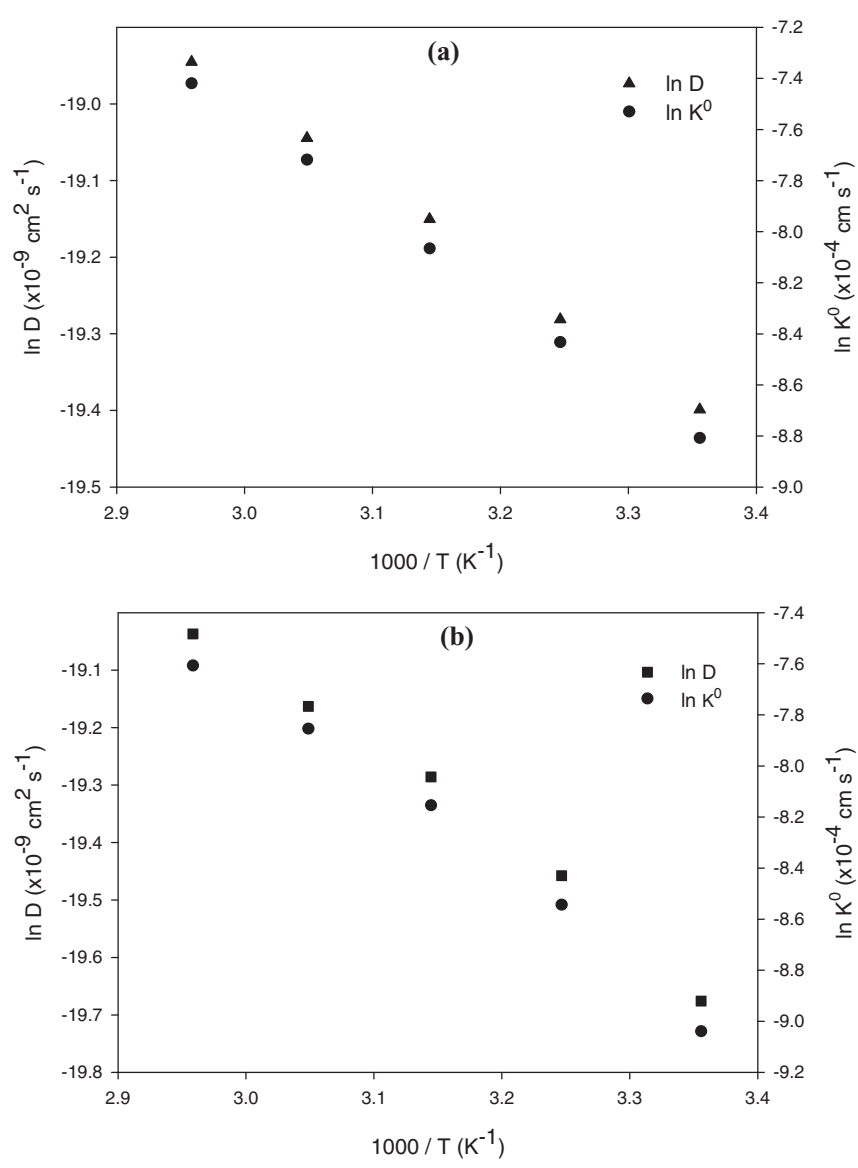

Figure 9. Dependence of diffusion and rate constant on temperature using Arrhenius rule for (a) $\mathrm{Fc}$ and (b) $\mathrm{Cc}^{+}$redox couples in $\mathrm{C}_{19} \mathrm{H}_{18} \mathrm{BrP} / \mathrm{TEG}$.

Evaluation of the heterogeneous rate constant for $\mathrm{FC}_{\mathrm{FC}}{ }^{+}$and $\mathrm{Cc}^{+} / \mathrm{Cc}$ : verification of the Arrhenius law. - Heterogeneous rate constants $\left(k^{0}\right)$ at stationary macro-electrodes are typically evaluated by applying the well-known Nicholson method, which is based on the degree of peak potential separation between cathodic and anodic reactions in a cyclic voltammogram for a simple one electron transfer process. ${ }^{46-49}$ The methodology, however, is susceptible to errors resulting from residual $R_{u}$ and charging currents, which can result in overstated rate constants. When the temperature of solutions of $\mathrm{Fc}$ and $\mathrm{Cc}^{+}$in DESs was varied and rate constants were estimated, it was possible to construct Arrhenius plots for the two redox couples. The temperature dependences of the rate constant of $\mathrm{Fc}$ and $\mathrm{Cc}^{+}$in $\mathrm{C}_{19} \mathrm{H}_{18} \mathrm{BrP} / \mathrm{TEG}$ are presented in Figures $9 \mathrm{a}$ and $9 \mathrm{~b}$ and nearly identical slopes were found in the $D$ and $k^{0}$ Arrhenius plots. In general, it was found that the rate constant rose with increasing temperature for both $\mathrm{Fc}$ and $\mathrm{Cc}^{+}$. The activation energy corresponding to the rate constant $\left(E_{k}\right)$ was then calculated from the slope and listed in Table VI.

\section{Conclusions}

Various physicochemical and electrochemical properties, such as viscosity, density, conductivity, molar conductivity, rate constant, and diffusion coefficients of $\mathrm{Fc}$ and $\mathrm{Cc}^{+}$in DESs, were evaluated over the temperature range from 298 to $363 \mathrm{~K}$. These results indicated that the $k^{0}$ and $D$ improved with increasing temperature in DESs. The validity of the Arrhenius law was confirmed by exploring the temperature dependences of $k^{0}$ and $D$. The activation energies $\left(E_{\eta}, E_{\sigma}, E_{D}\right.$, and $\left.E_{k}\right)$ for each DES were calculated from the slopes of the Arrhenius plots. The correlation of viscosity to conductivity was evaluated by using the Walden plot which serves as a practical means of evaluating the relative fluidity and degree of decoupling of ions of the tested DESs. A slight decrease in $\Delta E_{p}$ was observed with the increase of temperature while $E_{1 / 2}$ values changed to more negative potentials for oxidation of $\mathrm{Fc}$ and more positive potentials for the reduction of $\mathrm{Cc}^{+}$in DESs. Finally, kinetic parameters showed that DES with ethylene glycol as the hydrogen bond donor had consistently higher rate constants and lower activation energies than its tested counterparts. This meant that this DES could be a reasonable choice for further tests as both solvent and electrolyte for redox flow cells.

\section{Acknowledgments}

The authors are grateful for financial support from the High Impact Research grant (UM.C/HIR/MOHE/ENG/18) from the Ministry of Higher Education in Malaysia. MHC is grateful to Dr. Vladimir Yufit for helpful discussions regarding electrochemical measurements.

\section{References}

1. E. L. Smith, A. P. Abbott, and K. S. Ryder, Chem. Rev., 114, 11060 (2014).

2. A. P. Abbott, G. Capper, D. L. Davies, H. L. Munro, R. K. Rasheed, and V. Tambyrajah, Chem. Commun., 2010 (2001).

3. L. Bahadori, M. H. Chakrabarti, F. S. Mjalli, I. M. AlNashef, N. S. A. Manan, and M. A. Hashim, Electrochim. Acta, 113, 205 (2013).

4. I. M. AlNashef, M. L. Leonard, M. C. Kittle, M. A. Matthews, and J. W. Weidner, Electrochem. Solid State Let., 4, D16 (2001).

5. Q. Zhang, K. De Oliveira Vigier, S. Royer, and F. Jerome, Chem. Soc. Rev., 41, 7108 (2012).

6. M. H. Chakrabarti, N. P. Brandon, F. S. Mjalli, L. Bahadori, I. M. Al Nashef, M. A. Hashim, M. A. Hussain, C.T J. . Low, and V. Yufit, J. Solution Chem., 42, 2329 (2013).

7. P. M. V. Fernandes, J. M. Campiña, C. M. Pereira, and F. Silva, J. Electrochem. Soc., 159, G97 (2012)

8. A. P. Abbott, K. El Ttaib, G. Frisch, K. J. McKenzie, and K. S. Ryder, Phys. Chem. Chem. Phys, 11, 4269 (2009).

9. N. M. Pereira, P. M. V. Fernandes, C. M. Pereira, and A. F. Silva, J. Electrochem. Soc., 159, D501 (2012).

10. M. H. Chakrabarti, N. P. Brandon, M. A. Hashim, F. S. Mjalli, I. M. AlNashef, L. Bahadori, N. S. A. Manan, M. A. Hussain, and V. Yufit, Int. J. Electrochem. Sci., 8, 9652 (2013).

11. K. Pang, Y. Hou, W. Wu, W. Guo, W. Peng, and K. N. Marsh, Green Chem., 14, 2398 (2012).

12. D. Lindberg, M. de la Fuente Revenga, and M. Widersten, J. Biotechnol., 147, 169 (2010).

13. Y. Dai, J. van Spronsen, G.-J. Witkamp, R. Verpoorte, and Y. H. Choi, Anal. Chim. Acta, 766, 61 (2013)

14. A. P. Abbott, T. J. Bell, S. Handa, and B. Stoddart, Green Chem., 7, 705 (2005).

15. A. P. Abbott, G. Capper, D. L. Davies, K. J. McKenzie, and S. U. Obi, J. Chem. Eng. Data, 51, 1280 (2006).

16. Y. You, C. Gu, X. Wang, and J. Tu, J. Electrochem. Soc., 159, D642 (2012)

17. C. Rub and B. Konig, Green Chem., 14, 2969 (2012).

18. M. H. Chakrabarti, F. S. Mjalli, I. M. AlNashef, M. A. Hashim, M. A. Hussain, L. Bahadori, and C. T. J. Low, Renew. Sustain. Energy Rev., 30, 254 (2014).

19. L. Waligora, A. Lewandowski, and G. Gritzner, Electrochim. Acta, 54, 1414 (2009).

20. S. K. Sukardi, J. Zhang, I. Burgar, M. D. Horne, A. F. Hollenkamp, D. R. MacFarlane, and A. M. Bond, Electrochem. Commun., 10, 250 (2008).

21. E. I. Rogers, D. S. Silvester, D. L. Poole, L. Aldous, C. Hardacre, and R. G. Compton, J. Phys. Chem. C, 112, 2729 (2008).

22. V. M. Hultgren, A. W. A. Mariotti, A. M. Bond, and A. G. Wedd, Anal. Chem., 74, 3151 (2002).

23. A. A. J. Torriero, J. Sunarso, and P. C. Howlett, Electrochim. Acta, 82, 60 (2012).

24. C. A. Brooks and A. P. Doherty, Electrochem. Commun., 6, 867 (2004)

25. D. H. Zaitsau, G. J. Kabo, A. A. Strechan, Y. U. Paulechka, A. Tschersich, S. P. Verevkin, and A. Heintz, J. Phys. Chem. A, 110, 7303 (2006).

26. A. Deyko, K. R. J. Lovelock, J. A. Corfield, A. W. Taylor, P. N. Gooden, I. J. Villar-Garcia, P. Licence, R. G. Jones, V. G. Krasovskiy, E. A. Chernikova, and L. M. Kustov, Phys. Chem. Chem. Phys., 11, 8544 (2009).

27. R. M. Crooks and A. J. Bard, J. Electround. Chem., 243, 117 (1988).

28. N. Tsierkezos, J. Solution Chem., 36, 289 (2007).

29. Y. Wang, E. I. Rogers, and R. G. Compton, J. Electroanal. Chem., 648, 15 (2010).

30. M. Matsumiya, M. Terazono, and K. Tokuraku, Electrochim. Acta, 51, 1178 (2006).

31. A. P. Abbott, J. C. Barron, K. S. Ryder, and D. Wilson, Chemistry - A European Journal, 13, 6495 (2007)

32. L. Bahadori, N. S. Abdul Manan, M. H. Chakrabarti, M. A. Hashim, F. S. Mjalli, I. M. AlNashef, M. A. Hussain, and C. T. J. Low, Phys. Chem. Chem. Phys, 15, 1707 (2013).

33. K. Shahbaz, S. Baroutian, F. S. Mjalli, M. A. Hashim, and I. M. AlNashef, Thermochim. Acta, 527, 59 (2012)

34. T.-Y. Wu, S.-G. Su, Y.-C. Lin, H. P. Wang, M.-W. Lin, S.-T. Gung, and I. W. Sun, Electrochimica Acta, 56, 853 (2010). 
35. P. Bonhote, A.-P. Dias, N. Papageorgiou, K. Kalyanasundaram, and M. Gratzel, Inorg. Chem., 35, 1168 (1996).

36. M. A. Kareem, F. S. Mjalli, M. A. Hashim, and I. M. AlNashef, Journal of Chemical \& Engineering Data, 55, 4632 (2010)

37. T.-Y. Wu, S.-G. Su, H. P. Wang, Y.-C. Lin, S.-T. Gung, M.-W. Lin, and I. W. Sun, Electrochim. Acta, 56, 3209 (2011).

38. M. Yoshizawa, W. Xu, and C. A. Angell, J. Am. Chem. Soc., 125, 15411 (2003)

39. M. Anouti, M. Caillon-Caravanier, Y. Dridi, H. Galiano, and D. Lemordant, J. Phys. Chem. B, 112, 13335 (2008).

40. S. P. Ong, O. Andreussi, Y. Wu, N. Marzari, and G. Ceder, Chem. Mater. 23, 2979 (2011).

41. R. S. Stojanovic and A. M. Bond, Anal. Chem., 65, 56 (1993).
42. J. Zhang and A. M. Bond, Anal. Chem., 75, 2694 (2003).

43. A. J. Bard and L. R. Faulkner, Electrochemical Methods; 2nd ed.; Wiley: New York, 2001.

44. B. Keita, D. Bouaziz, and L. Nadjo, J. Electrochem. Soc, 135, 87 (1988).

45. D. Shoup and A. Szabo, J. Electroanal. Chem. Interfacial Electroche, 140, 237 (1982).

46. R. S. Nicholson, Anal. Chem., 37, 1351 (1965).

47. Y. Pan, W. E. Cleland, and C. L. Hussey, J. Electrochem. Soc, 159, F125 (2012).

48. D. Y. Kim, J. C. Yang, H. W. Kim, and G. M. Swain, Electrochim. Acta, 94, 49 (2013).

49. M. H. Chakrabarti, R. A. W. Dryfe, and E. P. L. Roberts, J. Chem. Soc. Pak., 29, 294 (2007). 